\title{
Crisis Management in High Reliability Organizations: Lessons from Brazilian Air Disasters
}

\begin{abstract}
Purpose: The focus of this study was to analyze crisis management in a context of HighReliability Organizations (HRO) evidenced in two cases of Brazilian air disasters. Aspects of human and technological natures were examined, addressing the complex socio-technical system.
\end{abstract}

Methodology: This in-depth case study addressed the two most serious air disasters on Brazilian territory. The first case involved a mid-air collision between Gol Flight 1907 and the Legacy jet. In the second case, TAM flight 3054 had difficulty braking when landing at the airport and crashed into a building. Data were collected from official disaster documents.

Findings: The results revealed that the management and operational activities aimed to maintain the necessary conditions that prioritize a high level of reliability. High reliability mainly involves concern over failure, reluctance to accept simplified interpretations, sensitivity to operations, commitment to resilience and detailed structure specifications.

Practical Implications: The implications are based on alerting highly reliable organizations, emphasizing the focus on managing more reliably, resiliently and conscientiously. Changes will be required in the operations of organizations seeking to learn to manage unexpected events and respond quickly to continually improve the responsiveness of their services.

Originality: In the perspective of an intrinsic case study for crisis management in a context of HRO and disaster risk management, the originality of this study lies in its examination of the paradoxical nature of control within the systems of dangerous operations in complex organizations, as well as their contradictions in a high-reliability system.

Keywords: crisis management; flight disasters; high-reliability; complex systems.

Article classification: Research paper 


\section{Introduction}

In environments such as airlines, hydroelectric or thermonuclear plants, disasters can result in an unforeseen sequence of random events and cause great catastrophes. Disaster risk derives from the magnitude, potential occurrence, frequency, speed and spatial extent of a harmful event or process, plus people's susceptibility to loss, injury or death (Wisner et al., 2012). Diversity of agents in permanent interaction can cause failure, and their behavior depends on human and technical conditions or the state of the parties. This means that the performance of these systems is often unpredictable (Allen, Maguire and Mckelvey, 2011, Ladyman et al., 2013).

Organizations, such as airlines, are always subject to the risks inherent to their activities and they strive to learn from failures and ensure that errors are not repeated in future events. Therefore, these organizations are considered complex systems - open and adaptive systems with a large number of elements, nonlinearity, unpredictability, and diversity of agents, whose behavior is determined by the nature of their interactions (Cilliers, 1998) - founded on the principles of high reliability, which are constantly challenging their management (Gherardi, 1998; Catino and Patriotta, 2013; Antonacopoulou and Sheaffer, 2014). These are High Reliability Organizations (HROs), in which processes are tightly coupled to ensure reliability.

In this paper, crisis management refers to managerial practices related to non-routine phenomena including critical decision making as well as activities linked to prevention, preparation and mitigation, seeking organizational recovery and change (Comfort, 1988). Furthermore, it is analyzed in the context of High Reliability Organizations as evidenced in two cases of Brazilian flight disasters. Aspects of human and technological natures, addressing the complex socio-technical system, were examined, providing important lessons for airlines and traffic control systems. These factors contributed to the occurrence of both disasters. The implications of these are relevant when it comes to managing crisis situations and HRO, especially those whose performance essentially depends on the reliability of these systems.

Two internationally notorious flight disasters occurred on Brazilian territory, causing considerable social repercussions with hundreds of deaths. The first case occurred in September 2006, involving the Boeing 737-800 and the Legacy 600. The airplanes collided in midair in the northwest of the country. The second disaster, which also had serious repercussions nationwide, occurred in July 2007, involving a TAM Airbus A320, Flight 3054 at Congonhas airport in São Paulo, surrounded by a densely populated area. Founded in 1936, it is considered the executive airport of Brazil due to the large number of its business travelers. In 2018, 600 aircraft landed and took off there every day, approximately 36 per hour. 21,637,662 passengers 
passed through the airport in 2018. When the disaster occurred, the plane underwent braking difficulties and skidded off the runway, crashing into a building located on the other side of the avenue next to the airport.

The main contribution of this study lies in the in-depth crisis management analysis of air disasters through the lens of the Normal Accident Theory (NAT) and High Reliability Organizations (HRO), exploring the lessons and implications of socio-technical system failures. In addition, the paradoxical nature of control within the systems of dangerous operations was examined, as well as their contradictions in a system of high reliability. The civil aviation system operates under tightly regulated rules and regulations, but continually makes room for technical failures, misconduct, neglected errors, and mistakes by humans or systems that become the source of disasters, making this system an extremely vulnerable one.

\section{Theoretical Foundation}

\subsection{High Reliability and Normal Accidents}

The air navigation system operates with risks that are not always explicit but are directly interlinked with their complexity. Complexity science provides relevant theoretical support for conducting systematic studies of complex systems, examining the circumstances in which phenomena of emergency and complexity occur (Abrahamsson, Hassel, and Tehler, 2010; Allen, Maguire and McKelvey, 2011). Normal Accident theory (NAT) and High-Reliability Theory (HRT) focus on the study of the causes of disasters in hazardous operations in complex systems (Areosa, 2012).

Systems with interactive complexity and tight coupling are subjected to unforeseen or unexpected accidents called "systems accidents" or "normal accidents" (Perrow, 1999). A tight coupling system is understood as a highly interdependent one, where each part of the system is closely linked to the other parts. As a result, any change in one part can impact the conditions of the other parts of the system (Marais, Dulac and Levenson, 2004), which makes the system more responsive to challenges because each part is less capable of responding in its own way (Orton and Weick, 1990).

On the other hand, loosely coupled systems have few variables in common or fewer tight links among themselves. Thus, such systems are able to absorb failures or unplanned behavior without losing stability (Marais, Dulac and Levenson, 2004). Consequently, being less responsive to challenges, they display more distinctiveness (Orton and Weick, 1990). What NAT does is explain what happens in a system when unintentional behavior causes a series of 
events that configure an accident (Perrow, 1999). Both theories help complex organizations build reliable systems by adapting and responding to unforeseen events.

In Normal Accident Theory (Weick, 2004), prevention could not be 100\% efficient in a system of complex interactions, given that interactions are unclear, unexpected or even unpredictable. Likewise, a tightly coupled system would be capable of transforming the magnitude of an event into something catastrophic and impossible to contain once it had begun, as the response time would be minimal. Disasters are considered normal events in some complex interactive environments and, particularly, in high coupling systems (Shrivastava, Sonpar and Pazzaglia, 2009). This observation led to questions regarding how these organizations, which use complex high-risk technology, manage to operate for long periods without accidents.

High-Reliability Theory seeks to answer this question by focusing on four aspects by managing performance, culture of responsibility, organizational learning and redundancy in a variety of aspects of activities of complex organizations (Weick and Sutcliffe, 2006). Organizations with lower rates of accidents are those that maintain risk awareness focused on reliability in operations and manage to maintain high levels of control in environments where there are no second chances (Roberts et al., 1994; Weick and Sutcliffe, 2007).

In this respect, while NAT is sustained more by structural and political dimensions, HRO is supported by a technical and behavioral aspect of complex systems (Sagan, 1993), although both theories are quite compatible (Rijpma, 2003; Areosa, 2012). While proponents of NAT do not preclude redundancy in high-risk systems, the proponents of HRO do not stress that complex organizations are free of failures. Disaster risk management practice is still very much dominated by reaction and response, to the detriment of development-based risk reduction and avoidance interventions (Oliver-Smith et al., 2016).

\subsection{Crisis Management, Failure and Learning in HRO}

Crises are typical features of today's society. Crisis management is the process through which organizations cope with unexpected or disruptive events that threaten their functioning, prestige and image (Catino, 2008). Failure and learning in complex systems pose a challenge to management due to the organizational characteristics and hazardous operations within this kind of system. In this context, learning is essential not only to understand disasters and errors but also for determining corrective processes founded on procedures and the culture of reliability (Haunschild and Sullivan, 2002). Through the learning processes that a complex system undergoes, it is possible to assume a more proactive HRO based approach. 
Furthermore, the process of analyzing disasters allows a rapid identification of failures that might be implicitly unknown to the organization and could lead to near misses or even latent errors (Pidgeon and O'Leary, 2000). Individuals together with technological and instrumental apparatuses are decisive when disasters occur. Thus, complexity theories like NAT and HRO have distinct but inter-related perspectives in their scope, allowing a better understanding of the nature of the events and what can be learned from failures and errors. Monitoring technical factors is clearly important to maintain high-reliability, but those interested in keeping control cannot think only in terms of technical control. They also have to be concerned with managerial controls (Turner, 1994).

Human errors in organizations are identified at two levels: personal and system approach. The personal approach concentrates on unsafe acts like errors and procedural violations by human beings. This behavior is the result of a lack of attention, negligence and recklessness. The system approach, on the other hand, is built on the premise that humans are fallible and that errors are made even in the best organizations (Reason, 2000). Therefore, errors are perceived more as a consequence than a cause and are less concentrated on the perversity of human nature and more on "upstream systemic factors" (Reason, 2000: 768). Wisner, Gaillard and Kelman (2012) indicated that disaster risk can be analyzed from different perspectives, distinct actors and contexts.

\section{Method}

This qualitative case study (Creswell and Poth, 2017) aimed to examine crisis management in the context of high-reliability organizations evidenced in two cases of flight disasters in Brazil. These flight disasters were intentionally selected because of their international repercussion and impact on the Brazilian community, which has an average of one flight accident every two days (FOLHA DE SÃO PAULO, 2018). This is a perspective of an intrinsic case study in which each case involves a unique or unusual situation (Stake, 1994). Data were gathered in the form of official documents related to the Flight Disasters. The data analysis and interpretation process are shown in Figure 1.

\section{[Insert Figure 1 about here]}

Following the description, the data analyses were segmented by specific themes, aggregating information into large clusters of ideas and providing details that support the themes. Stake (1994: 123) calls this analysis the "development of issues". In the Cross-Case 
process, similarities and differences between the two cases were described and analyzed. This involved examining themes across cases to discern those that are common and different to all cases (Creswell and Poth, 2017).

To analyze the cases, the socio-technical aspects were observed, as well as the temporal sequence of the events leading up to the crashes. A socio-technical disaster is considered a manmade disaster and an industrial crisis in which the community is involved (Shaluf, Ahmadun and Said, 2003). An industrial disaster is known as a crisis-related phenomenon and may develop into a crisis; it is then called an industrial crisis, an industrial crisis that results from socio-technical disasters (Quarantelli, 1988). Crises may develop because of political and economic issues, as well as from disasters, as demonstrated in Figure 2.

\section{[Insert Figure 2 about here]}

Case studies often end with conclusions formed by the researcher regarding the overall meaning derived from the cases. These are called "assertions" by Stake (1994), with the researcher providing an interpretation of the data couched in terms of personal views or in terms of constructs in the literature. These can be considered general lessons learned from studying the cases (Creswell and Poth, 2017).

The Brazilian Aviation System is made up of public organizations such as ANAC (National Agency for Civil Aviation), which is in charge of setting policies, rules and regulations plus supervision of the civil aviation system in the country, and CENIPA (Center for Investigation and Prevention of Aviation Accidents). This is a federal agency in charge of analyzing investigations, developing reports and policies seeking the high-reliability of the system. Another federal organization is Infraero, which is in charge of administering the whole system of airports in the country.

\section{[Insert Figure 3 about here]}

\subsection{Cases}

In this study, two cases are contrasted in an attempt to identify both regularities and differences. The cases belong to the same domain and occurred in the same geographical context, thus making comparisons possible. Two case studies were analyzed, one involving Gol Flight 1907 and the Legacy jet, and the other being TAM Flight 3054, which will be referred to as Case 1 and Case 2, respectively. The main comparative case dimensions are shown in Table 1. 
[Insert Table 1 about here]

Case 1

The case 1 occurred on 29 September 2006, when Gol Flight 1907 left Manaus, Brazil, in the state of Amazonas, in the northwest of the country, for Rio de Janeiro with 148 passengers and six crew on board, with a planned stopover in Brasília, Federal District. Meanwhile, the Legacy jet took off from São José dos Campos in São Paulo State, Brazil, for Fort Lauderdale in the USA (ANAC, 2008). The Legacy jet was manufactured by the Brazilian company Embraer and sold to Excelaire, an American air taxi company. This company sent two experienced pilots to Brazil for the flight to the United States. During the days preceding take off, both pilots familiarized themselves with the technical functions of the aircraft, including the accident prevention system, TCAS. Following a thorough recognition of the aircraft, the Legacy initiated the take-off procedure and followed its route. Meanwhile, Gol Flight 1907 was on a routine journey with its crew, in compliance with the technical regulations required for take-off procedure, and followed its normal route (ANAC, 2008; CENIPA, 2008; Sant'Anna, 2011).

[Insert Figure 4 about here]

Case 2

The case 2 occurred on 17 July 2007, when TAM Flight 3054, with 181 passengers and 6 crew on board, was travelling from Porto Alegre in Rio Grande do Sul State to São Paulo, Brazil. It was a routine flight. The airplane rose to the correct altitude and remained at cruise speed for forty minutes before beginning its landing procedure. At 18:43, the pilots began reviewing the checklist for landing and touched down soon afterwards. However, the plane had difficulty in braking, veered to the left, skidded off the runway and crashed into a building on the other side of the airport avenue (ANAC, 2009; CENIPA, 2009; Sant'Anna, 2011). After the disaster, ANAC determined that only pilots with over 100 hours of flight experience and who have practiced go-arounds after the landing gear has touched down may land or take off with Boeing and Airbus at Congonhas airport (ANAC, 2009; CENIPA, 2009). A new control tower was opened at the airport in 2013, and the main runway was reformed again to prevent the build-up of water. 


\section{Findings}

\subsection{Crisis from Human Errors}

Case 1 - The Legacy jet, at the time of the disaster, was not at the correct altitude, which should have been achieved after flying $480 \mathrm{~km}$ to the northeast of Brasília. There was no warning from the control system and the technical report shows that the controller responsible for paying attention to the altitude of the Legacy was concentrating on a Brazilian Air Force flight for which he was also responsible. This flight was on a mission to gather radar images near Brasília. As a result, the controller did not notice that the signal from the Legacy flight had "vanished" from the radar and was not sending accurate data. This failure continued without due attention following the change of shift when the next controller took over from his colleague (ANAC, 2008; CENIPA, 2008; Sant'Anna, 2011).

The standard time for reporting a change in route should not be long, considering the possibility of a crash. Even so, during the flight, there was no communication between the two control towers and the jet. In the reports, the flight controllers' poor mastery of the English language was observed, and there was little or no understanding of the information given by the crew of the Legacy. At that time, it would have been possible to share information on the correction of the route, speed or traffic that would be important to the operation of the aircraft. This was not done by either party. Effective communication between the controllers and the controllers and the aircraft, would have mitigated the risk of an accident (ANAC, 2008; CENIPA, 2008; Sant'Anna, 2011).

Case 2 - At the time of the disaster, the levers were not correctly positioned for the landing maneuver. Therefore, when it touched down, the plane did not have sufficient braking action to complete the process. Before reaching the end of the runway, the pilot shifted the lever to the left and swerved onto the grass before crashing into the building (ANAC, 2009; CENIPA, 2009). In São Paulo, the conditions of the runway at Congonhas airport were not entirely favorable for landing at that time as it was a stormy day. The main complaint registered was related to the grooving system. This should have been sufficient justification for the closure of the airport, but the complaint was not given due attention. The Center for the Investigation and Prevention of Aeronautic Accidents (CENIPA) drafted a report that pointed out the main causes of the disaster. These included the wrong position of the levers prior to landing and the fault of the Brazilian Airport Infrastructure Company (Infraero) regarding the recommendation to close the airport due to the conditions of the runway on rainy days (ANAC, 2009; CENIPA, 2009; Sant'Anna, 2011). 


\subsection{Crises due to Technical Failures}

Case 1 - Two technical faults were directly involved in the disaster. First, the lack of technical knowledge of the Legacy jet meant that the pilots had to undergo intensive training with regard to its main functions before departure. Despite the pilots' lack of knowledge of the aircraft, the plane took off and remained at the programmed altitude until it drew near to Brasília, when the pilots were instructed, through information received from the control tower in Brasília, to shift from an altitude of eight thousand feet to thirty-eight thousand feet between Brasília and Manaus. To report the altitude error, the transponder on the aircraft should have transmitted signals to the tower, which was responsible for advising both aircraft of the corrective maneuver. However, after passing through Brasília, the transponder of the Legacy was switched off by the pilots. This was the second decisive event leading up to the disaster because with the transponder turned off the anti-collision system was not working. This led to the planes crashing in midair (ANAC, 2008; CENIPA, 2008; Sant'Anna, 2011).

Case 2 - The inadequate positioning of the levers during the braking of the aircraft in the landing process was the main factor in the incomplete procedure. The left-hand lever was in the IDLE position, activating the reverser of the left engine, while the right thrust lever was in a position with $80 \%$ power. Due to the bad procedure, the flight computer understood that the plane was executing a go-around and did not reduce speed correctly. Later investigations found that the plane had had a defect in the thrust reverser of the right engine since 13 July. The flaw had been detected by the aircraft's own electronic checking system, but the plane continued to fly in the following days, with the right thrust reverser deactivated, in compliance with a suggestion from the manufacturer (ANAC, 2009; CENIPA, 2009; Sant'Anna, 2011).

\subsection{Crises due to the Socio-Technical System}

Case 1 - It was observed in this case that several warning signs were not interpreted in time. Disasters tend to occur when the symptoms of failures and errors are ignored (Turner, 1978). Therefore, disasters may have an incubation period during which errors go unnoticed. At this time, warning signs may be dismissed as casual incidents or until they reach irreversible scales. In Case 1, the signs were appearing in the Brazilian air traffic control system.

Air traffic controllers are professionals responsible for the safe, orderly and swift guidance of aircraft in transit at the country's airports. They communicate directly with pilots to provide them with the information and instructions necessary for each aircraft to complete 
its flight and prevent crashes and other incidents. However, while air traffic control activities were executed without major incidents, flaws in the system itself were ignored and latency developed, culminating in the disaster between the Boeing 737 and the Legacy in 2006. (ANAC, 2008; Sant'Anna, 2011). The increasing flight traffic at the major airports was resulting in extremely stressful psychological and technical demands. The long workdays, low pay and precarious equipment were fueling great discomfort among the flight operators.

Case 2 - Two weeks before the disaster, the new runway at Congonhas airport was reopened following a major and expensive reform to make it a safer airport. Despite the reform, the pilots claimed that there were problems because it was reopened without grooving strips, which give planes a better grip on the runway.

On the day before the disaster, another plane had skidded at the same place, leading to the closure of the airport. A few minutes before the disaster, Infraero was asked to measure the layer of water on the runway to evaluate the need to suspend landings and departures. The measurement was made, but operations were not suspended. The same plane, on the previous day, had also experienced difficulty landing, with the plane coming to a complete halt only a few meters away from the end of the runway. The media pointed out that the defect in the thrust reverser was the cause of the problem on very slippery surfaces (ANAC, 2009; Sant'Anna, 2011).

\section{Discussion}

\subsection{Reliability in Crisis Situations}

High-Reliability in complex organizations has been explored, particularly in hazardous systems like nuclear plants, commercial air transportation and air traffic control (Pidgeon and O'Leary, 2000; Haunschild and Sullivan, 2002; Roberts, 2011; Catino and Patriotta, 2013). Despite awareness of vulnerability to failures and disasters, these conditions are not automatically considered as learning when it comes to avoiding catastrophes (Wisner et al., 2012).

The complexity of the scenarios of flight disasters is directly affected by social and technical aspects (Vaughan, 1999). Regarding the social aspects, a relevant point for consideration is the importance given to so-called "non-accidents". Organizational policy should incorporate means to promote, both formally and informally, forms of reporting that can help prevent further disasters. Moreover, the lack of a consolidated communication system could be a potential incubator for disasters (Turner, 1994; Netten and Van Someren, 2011). In 
terms of technical elements aircraft have black boxes, which can record dialogue between the pilots, serving as a primary source of evidence in cases of disasters.

In the two cases, there was a certain "incredulity" regarding the possibility of a disaster occurring, promoted perhaps by the sequence of time free of risks. Examples of this were found in the first case, when the pilots of the Legacy jet followed their protocols of knowledge of the new aircraft and did not delay or postpone their flight to obtain full knowledge of its technical functions. Likewise, the flight controllers had the opportunity to report the corrected altitude of the Legacy flight while the signal was being transmitted. They also did not make contact to find out the reason for the disappearance of the flight's data, which is a standard procedure established by ANAC. In addition, in Case 2, high-reliability protocols were breached when warnings about wet runway closure were ignored for fear of loss of efficiency at the expense of reliability. In this context, a model is proposed that demonstrates multi-facets of crisis management in HRO, as a complex system, presented in Figure 5.

\section{[Insert Figure 5 about here]}

The internal arrows demonstrate the pressure that HRO undergo to maintain reliability. These pressures are represented by unexpected events, failures and errors (socio-technical system), crisis situations and unpredictable actions. However, the aspects that permeate an HRO are represented by the larger outer arrows, which flow from within the organization. These aspects are culture of reliability, redundancy and responsibility. These elements promote effective crisis management, from human to technical elements, in this type of complex system such as civil aviation.

However, theories such as High Reliability Theory (HRT) demonstrate that preventive attitudes can be effective in containing errors and failures. This leads to benefits of organizational learning, which are not easy to achieve. Disasters result from the very nature of complex and tightly coupled systems. In such a context, there is always the risk of individual misconduct before normal or emergent situations result in disasters (Roberts, Bea and Bartles, 2001). Cases such as the Bhopal Disaster (1984), the Tenerife Air Disaster (1977), the Space Shuttle Columbia Disaster (2003), and the Air France Disaster (2009) are classic examples of problems in complex systems that occurred due to a combination of human errors, technical failures, unstable environment, and negligence, all of which contributed greatly to the disasters.

Complex systems like civil aviation operate based on a multi-faceted dynamic process involving cognitive, emotional, technical, social and political dimensions that impact the 
behavior of these systems and their parts. Managing them requires a huge effort to combine all dimensions and put in place strategies and procedures to achieve greater reliability in complex organizations such as airlines and flight control systems.

\subsection{Lessons for crisis management in HRO}

What can be learned from flight disasters that will aid crisis management? This question moves us as individuals and affects organizations and the civil aviation system because different emotional factors come into play at these times, affecting rationality. The simple fact of creating a space to reflect on a major tragedy encourages us to learn naturally and spontaneously. In both cases, it is important to note how quickly the events occurred that culminated in losing control of the situation (Oliver et al., 2017). In the two cases, after the initial incident, little could be done for the aircrafts to remain stable. Human and technical factors, in a tightly coupled system, caused significant interference that led the entire complex system to destabilize (Perrow, 1999).

The cases in question revealed that civil aviation is a vulnerable system. Due to the nature of its operations, it is a highly sensitive system to unexpected events, surprises and human errors. The main lesson from Case 1 (Gol/Legacy disaster) indicated that human errors in the air control system (CINDACTA) were critical, contributing to the accident as was revealed by the formal investigation (CENIPA). The incorporation of a culture focusing on high sensitivity to operations coping with expectations and mindfulness would contribute to a greater reliability of the traffic control system.

In Case 2 (TAM disaster), two critical problems were identified: the conditions of the runway at Congonhas airport and the lack of experience of the pilots, who did not handle the position of the levers correctly (CENIPA). The problem of the runway was essentially a responsibility of Infraero, which did not meet the requirement of CENIPA to close the airport on days of heavy rain. In the second, case a decision was made by ANAC to require only experienced pilots to land and take off at the airport.

Poor handling of technical equipment, combined with the failures of the flight operators and other Brazilian air navigation agents, in both cases, aggravated the errors to the point of irreversibility. Therefore, for the management of complex systems, attention to failures is the main lesson to be learned. This is why human, technical and managerial elements to create a culture of reliability were highlighted. As a result, the main lessons learned for crisis management in the two situations in question are presented in Table 2. 


\section{[Insert Table 2 about here]}

In a socio-technical system, an individual component could be involved at every level of a disaster. Consequently, not only can the mind of an individual involved in high-risk environments cause disasters, but can also prevent or mitigate them (Weick, 1988). In Case 1, reports claimed that after the collision there was no possibility for Gol Flight 1907 to correct the errors before it fell. In Case 2, however, there was a period of 30 seconds between the perception that something was wrong and the crash. Therefore, there is evidence of how a tightly coupled system triggers a sequence of failures in a short space of time, making it difficult or impossible to correct errors. Therefore, how do errors and disasters occur? Indeed, human actions are intended to reduce errors, but there is no evidence or guarantee that these errors will be entirely eliminated. Therefore, the most important and best action that individuals can take is to try to understand the origin of these failures and contain them (Weick, 1988).

Redundancies for the high-reliability mechanisms are important in disaster prevention. However, the redundancy itself can increase the complexity of the context (Rijpma, 1997). Nevertheless, the challenge of learning from failures is not as simple and straightforward as some analyses may indicate (Madsen and Desai, 2010). It can be inferred that a culture of reliability sometimes exists, but negligent management heightens the possibility of disasters occurring. Especially with regard to Case 2, the managerial practices of the airline and deficiencies in the airport infrastructure contributed to the resulting disaster. In this case, the airline publicly sought economic efficiency in terms of excess aircraft fuel, in spite of highreliability protocols. Likewise, the airport infrastructure was negligent concerning the signs of error. It had been advised to close the airport under its existing conditions but did not comply with the reliability regulations (ANAC, 2009).

However, how can events like this be avoided? Can any lessons be learned from this disaster? The answer lies in the question. The desire to seek information and knowledge regarding disasters is a form of avoiding greater misfortunes. The dissemination of management focused on high reliability is indispensable in complex systems. This implies going beyond the prescriptive aspects of the theories. It means practicing a culture in which aspects relevant to operations and human behavior that affect organizational performance are systematically observed and monitored to reduce the risk of errors and disasters (Muro and Meyer, 2011).

The occurrence of both disasters analyzed in this paper led to lessons learned and corrective actions. First, following the events of Case 1, ANAC had to improve its air traffic control and regulations for critical conditions, as well as respond to the latency that was ignored 
for a long period of time. Following the events of Case 2, the airline had to improve its failure detection mechanisms and review its fuel policy. Furthermore, Infraero put a structural reinforcement in place on the runway of Congonhas airport.

\section{Conclusions}

Well-known cases like the Bhopal Disaster (1984), the Tenerife Air Disaster (1977), the Space Shuttle Columbia Disaster (2003), and the Air France Disaster (2009) are classic examples of a combination of human errors and technical failures. There is a tendency to avoid potential individual culpability by classifying hazardous situations as technically correct and covering up human errors (Tamuz, 2001). By covering up their own errors, managers of complex systems tend to attribute them to the complexity of the system.

In this paper, the two most critical Brazilian aviation disasters were analyzed and discussed. This study contributed to a wider debate on crisis management in the context of HRO, which despite being a highly regulated and formalized sector is always subject to errors (Vaughan, 1999). The errors that led to the disasters in question served as lessons for individuals and organizations operating in a complex system. Managerial and operational activities were intended to maintain the necessary conditions that prioritize a high level of responsibility and redundancy. This involves concern over flaws, reluctance to accept simplified interpretations, sensitivity to operations, commitment to resilience and detailed specifications of the structure.

The creation of a culture of reliability in a complex system acts as a way of learning from such errors at the individual, organizational and social levels. It is important not only to the aviation system but also to society. Likewise, it is necessary to review the public policy that regulates the sector and for the agency responsible for supervising policy in that field to renew its technology to make this complex civil aviation system more reliable.

Unpredictable or unexpected events will occur and risks will exist. The aviation system, as a complex system, needs to continuously improve its hazardous operations and crisis management in order to make the system more reliable. A critical question remains that continues to challenge the management of complex systems: "How safe is safe enough?" (Douglas, 1992: 41). It should be noted that the increasing vulnerability of a system, associated with a sequence of failures and partial understanding of other events, increases the chances of an imminent disaster (Wisner et al., 2012). Even though organizational management focuses on preventing disasters, an environment prone to disasters can be created imperceptibly, in which minor failures can instigate something much larger and disastrous. 
This study paves the way for future research with the approach of high reliability theory applied in different contexts. In addition, elaborating on the existing conditions of interconnections among the agents who make up the civil aviation system with a focus on levels of autonomy and interdependency to think and act in the system could be a fertile field of research. Another relevant approach would be to examine paradoxes, conflicts and tensions within and between organizations, and particularly how such elements are undermining control and reliability procedures.

\section{References}

Abrahamsson, M., Hassel, H. and Tehler, H. (2010), "Toward a system-oriented framework for analysis and evaluating emergency response", Journal of Contingencies and Crisis Management, Vol. 18 No. 1, pp. 14-25.

Allen, P., Maguire, S. and Mckelvey, B. (2011), Handbook of complexity and management, London: Sage Publications.

ANAC (2008), "Relatório Final A-022/CENIPA/2008", available at: http://media.folha.uol.com.br/mundo/2008/12/10/relatorio_voo_1907.pdf (accessed 14 February 2019).

ANAC (2009), "Relatório Final A - No 67/CENIPA/2009”, available at: http://www.anac.gov.br/assuntos/paginas-tematicas/gerenciamento-da-segurancaoperacional/relatorio-de-acidentes/arquivos/2007/pr-mbk.pdf (accessed 14 February 2019).

Antonacopoulou, E. and Sheaffer, Z. (2014), "Learning in crisis: Rethinking the relationship between organizational learning and crisis management", Journal of Management Inquiry, Vol. 23 No. 1, pp. 5-21.

Areosa, J. (2012), "O contributo das ciências sociais para a análise de acidentes maiores: dois modelos em confronto”, Análise Social, Vol. 204 No. 3, pp. 558-584.

Catino, M. (2008), “A review of literature: individual blame vs. Organizational function logics in accident analysis", Journal of Contingencies and Crisis Management, Vol. 16 No. 1, pp. 53-62.

Catino, M. and Patriotta, G. (2013), "Learning from Errors: Cognition, emotions and safety culture in the Italian Air Force", Organization Studies, Vol. 34 No. 4, pp. 1-31.

CENIPA (2008), "Relatório A-22/CENIPA/2008/PRGTD", available at: http://prevencao.potter.net.br/relatorio/page/39 (accessed 09 October 2017).

CENIPA (2009), "Relatório A-67/CENIPA/2009/PRMBK", available at: http://prevencao.potter.net.br/relatorio/page/38. (accessed 09 October 2017). 
Cilliers, P. (1998), Complexity and postmodernism: Understanding Complex Systems, London: Routledge.

Creswell, J. and Poth, C.N. (2017), Quality inquiry and research design: Choosing among five approaches, Sage Publications: C.A.

Comfort, L.K. (1988), Managing disaster: Strategies and policy perspectives, Durham, NC: Duke University Press.

Douglas, M. (1992), Risk and blame: Essays in Cultural Theory, London: Routledge.

FOLHA DE SÃO PAULO (2018), "Em dez anos, país tem média de um acidente aéreo a cada dois dias", available at: https://www1.folha.uol.com.br/cotidiano/2018/11/em-dez-anos-paistem-media-de-um-acidente-aereo-a-cada-dois-dias.shtml. (accessed 20 October 2018)

Gherardi, S., Nicolini, D. and Odella, F. (1998), "What do you mean by safety? Conflicting perspectives on accident causation and safety management in a construction firm", Journal of Contingencies and Crisis Management, Vol. 6 No. 4, pp. 202-213.

Haunschild, P.R. and Sullivan, B.N. (2002), "Learning from Complexity: Effects of Prior Accidents and Incidents on Airlines' learning”, Administrative Science Quarterly, Vol. 47 No. 4, pp. 609-643.

Ladyman, J., Lambert, J. and Wiesner, K. (2013), "What is a complex system?”, European Journal for Philosophy of Science, Vol. 3 No. 1, pp. 1-37.

Madsen, P.M. and Desai, V. (2010), "Failing to learn? The effects of failure and success on organizational learning in the global orbital launch vehicle industry", Academy of Management Journal, Vol. 53 No. 3, pp. 451-476.

Marais, K., Dulac, N. and Levenson, N. (2004), "Beyond normal accidents and high reliability organizations: The need for an alternative approach to safety in complex systems", In: Engineering Systems Division Symposium, MIT Cambridge, MA, pp. 1-16.

Muro, P.M. and Meyer Jr., V. (2011), “Organizações complexas e confiabilidade organizacional: Reflexões sobre as HRO - High Reliability Organizations”, Revista de Negócios, Vol. 16 No. 2, pp. 86-98.

Netten, N. and Van Someren, M. (2011), "Improving Communication in Crisis Management by Evaluating the Relevance of Messages", Journal of Contingencies and Crisis Management, Vol. 19 No. 2, pp. 75-85.

Oliver, N., Calvard, T. and Potockik, K. (2017), "Cognition, Technology, and Organizational Limits: Lessons from the Air France 447 Disaster”, Organization Science, Vol. 28 No. 4, pp. 729-743.

Oliver-Smith, A., Alcántara-Ayala, I., Burton, I. and Lavell, A.M. (2016), "Forensic Investigations of Disasters (FORIN): A conceptual framework and guide to research", IRDR FORIN Publication, No. 2. Beijing: Integrated Research on Disaster Risk. 
Orton, J.D. and Weick, K.E. (1990), "Loosely coupled systems: A reconceptualization”, Academy of Management Review, Vol. 15 No. 2, pp. 209-223.

Perrow, C. (1999), Normal Accidents: Living with High-Risk Technologies, Princeton, NJ: Princeton University Press.

Pidgeon, N.F. and O’Leary, M. (2000), “Man-Made Disasters: Why Technology and Organizations (Sometimes) fail”, Safety Science, Vol. 34 No. 1, pp. 15-30.

Quarantelli, E.L. (1988), "Disaster crisis management: a summary of research findings", Journal of Management Studies, Vol. 25 No. 4, pp. 373-384.

Rijpma, J.A. (1997), “Complexity, Tight-Coupling and Reliability: Connecting Norma Accidents Theory and High Reliability Theory", Journal of Contingencies and Crisis Management, Vol. 5 No. 1, pp. 15-23.

Rijpma, J.A. (2003), "From Deadlock to dead end: The normal accidents-high reliability debate revisited", Journal of Contingencies and Crisis Management, Vol. 11 No. 1, pp. 37-42.

Reason, J. (2000), "Human error: models and management", Business Management Journal, Vol. 320 No. 1, pp. 768-770.

Roberts, K.H., Rousseau, D.M. and La Porte, T.R. (1994), “The Culture of High Reliability: Quantitative and Qualitative Assessment Aboard Nuclear Powered Aircraft Carriers", The Journal of High Technology, Management Research, Vol. 5 No. 1, pp. 141-161.

Roberts, K.H., Bea, R. and Bartles, D.L. (2001), "Must accidents happen? Lesson from high reliability organizations”, Academy of Management Executive, Vol. 15 No. 3, pp. 70-79.

Roberts, K.H. (2011), "High reliability organizations (HROS)", Best Practice \& Research Clinical Anaesthesiology, Vol. 25 No. 2, pp. 133-144.

Sagan, S. (1993), The Limits of Safety: Organizations, Accidents, and Nuclear Weapons, Princeton, NJ, Princeton University Press.

Sant’Anna, I. (2011), “Cadeia de Erros”, Revista Piauí, Vol. 57 No. 1, pp. 12-20.

Shaluf, I.M., Ahmadun, F. and Said, A.M. (2003), “A review of disaster and crisis”, Disaster Prevention and Management: An International Journal, Vol. 12 No. 1, pp. 24-32.

Shrivastava, S., Sonpar, K. and Pazzaglia, F. (2009), "Normal Accident Theory versus High Reliability Theory: A resolution and call for an open systems view of accidents", Human Relations, Vol. 62 No. 9, pp. 13-57.

Stake, R.E. (1994), Case Studies, In: Denzin, N. K.; Lincoln, Y. S. (ed.) Handbook of qualitative research. Newsbury Park: Sage, pp. 236-247.

Tamuz, M. (2001), Defining away dangers: A study in the influences of Managerial Cognition on Information Systems, In: T.K. Lant and Z.Shapira(eds.) Organizational Cognition:

Computation and Interpretation, Mahwah, NJ: Lawreence Erelbaum, pp. 157-183. 
Turner, B.A. (1978), Man-Made Disasters, Ed. Wykheham.

Turner, B.A. (1994), “Causes of disaster: Sloppy management”, British Journal of Management, Vol. 5 No. 3, pp. 215-219.

Vaughan, D. (1999), “The dark side of organizations: Mistake, misconduct, and disaster", Annual Review of Sociology, Vol. 25 No. 1, pp. 271-305.

Weick, K.E. (1988), "Enacted sensemaking in crisis situations", Journal of Management Studies, Vol. 25 No. 4, pp. 305-317.

Weick, K.E. (2004), "Normal Accident Theory as Frame, Link and Provocation", Organization \& Environment, Vol. 17 No. 1, pp. 27-31.

Weick, K.E. and Sutcliffe, K.M. (2006), "Mindfulness and the Quality of Organization Attention”, Organization Science, Vol. 17 No. 4, pp. 514-524.

Weick, K.E. and Sutcliffe, K.M. (2007), Managing the unexpected: Resilient Performance in an Age of Uncertainty, San Francisco: Jossey-Bass.

Wisner, B., Gaillard, JC. and Kelman, I. (2012), Framing disaster: theories and stories seeking to understand hazard, vulnerability and risk, The Routledge Handbook of Hazards and Disaster Risk Reduction Routledge. 
Figure 1 - Coding Case Study approach

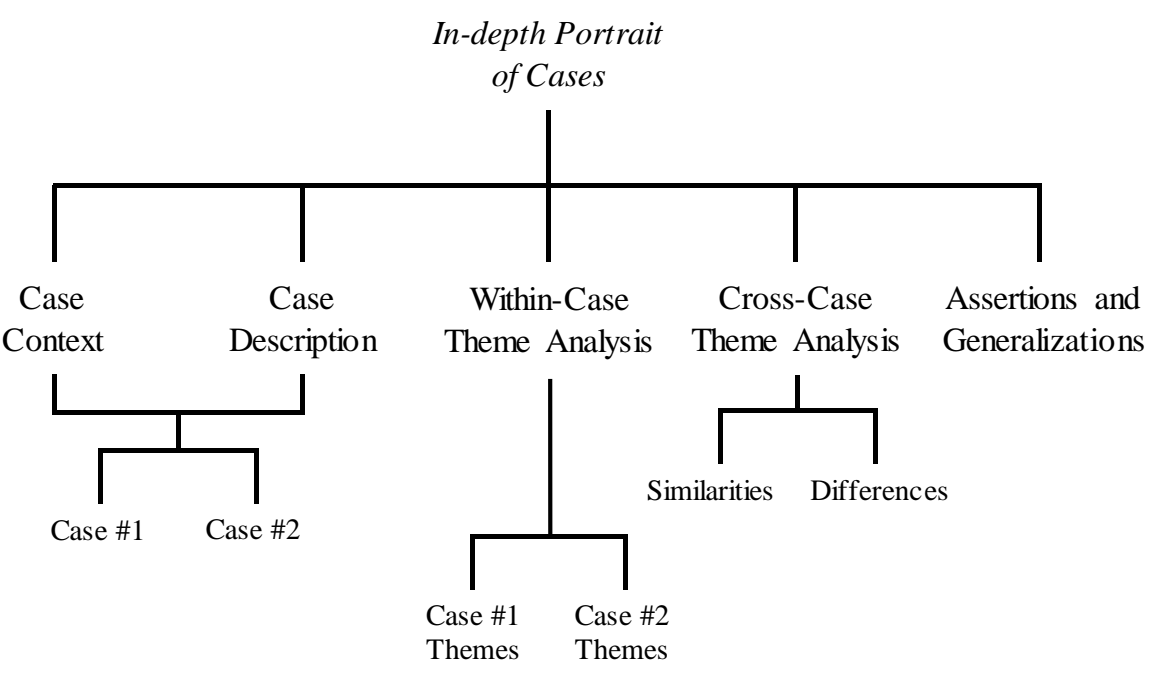

Source: Creswell and Poth (2017). 
Figure 2 - Types of crisis

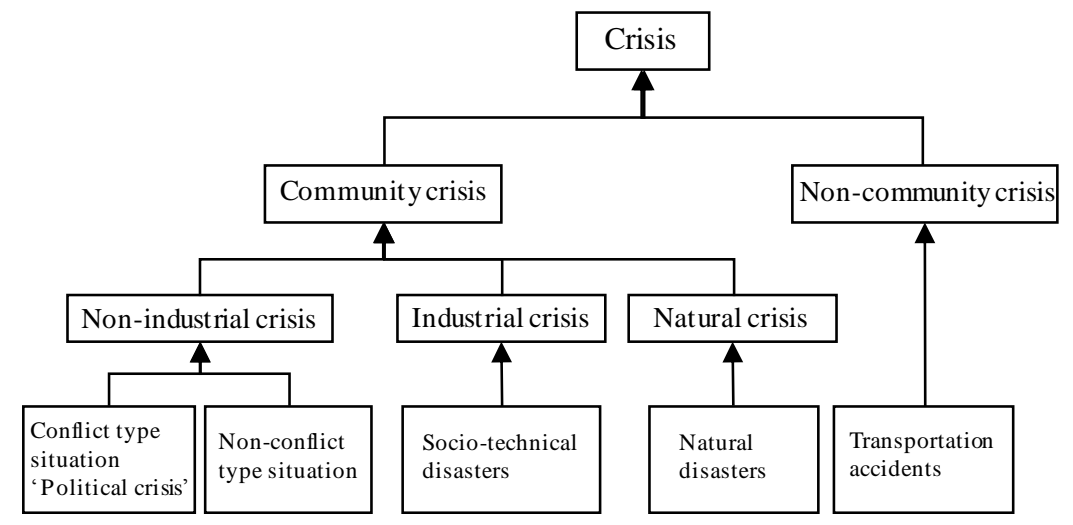

Source: Adapted from Shaluf, Ahmadun and Said (2003). 
Figure 3 - Ministry of Defense Structure

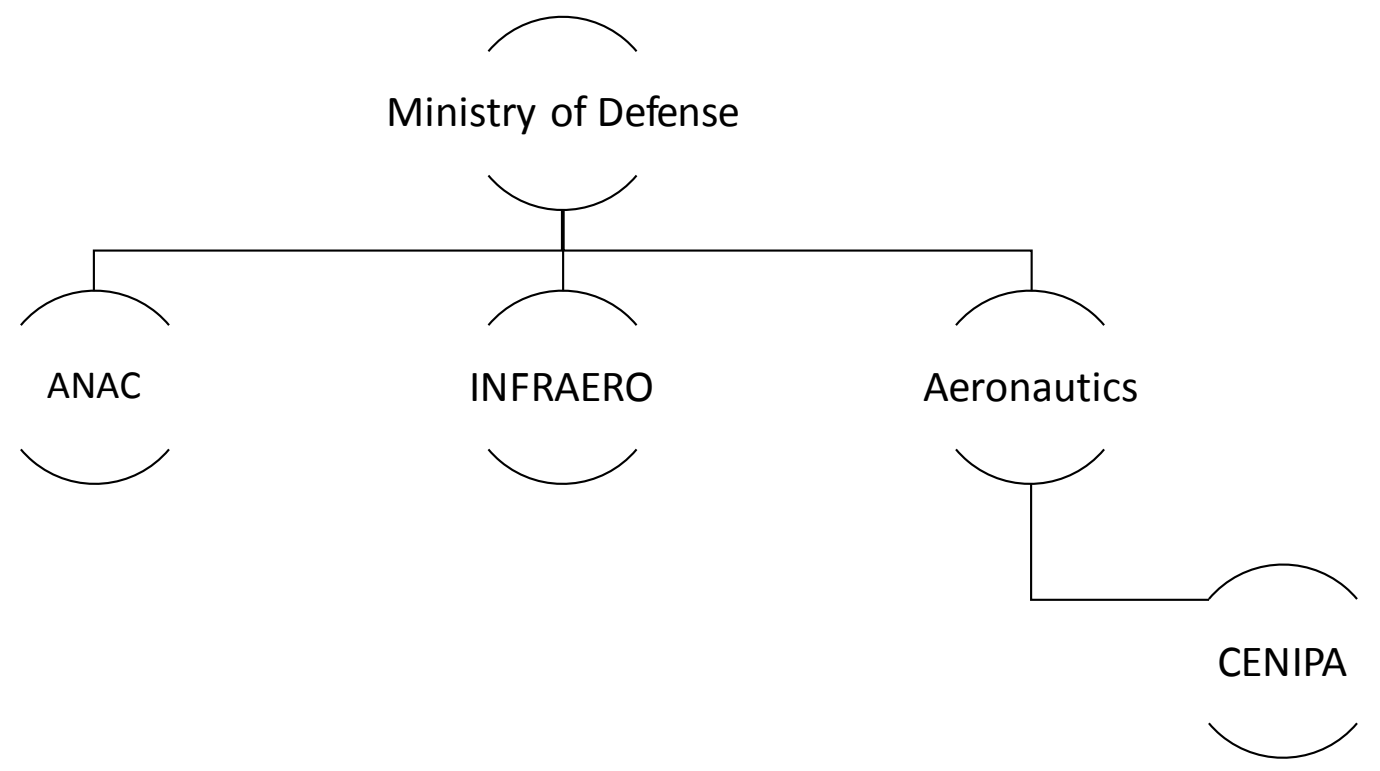

Source: Prepared by the authors. 
Figure 4 - Brazil map with flight routes

\section{Gol Flight and Legacy Jet}
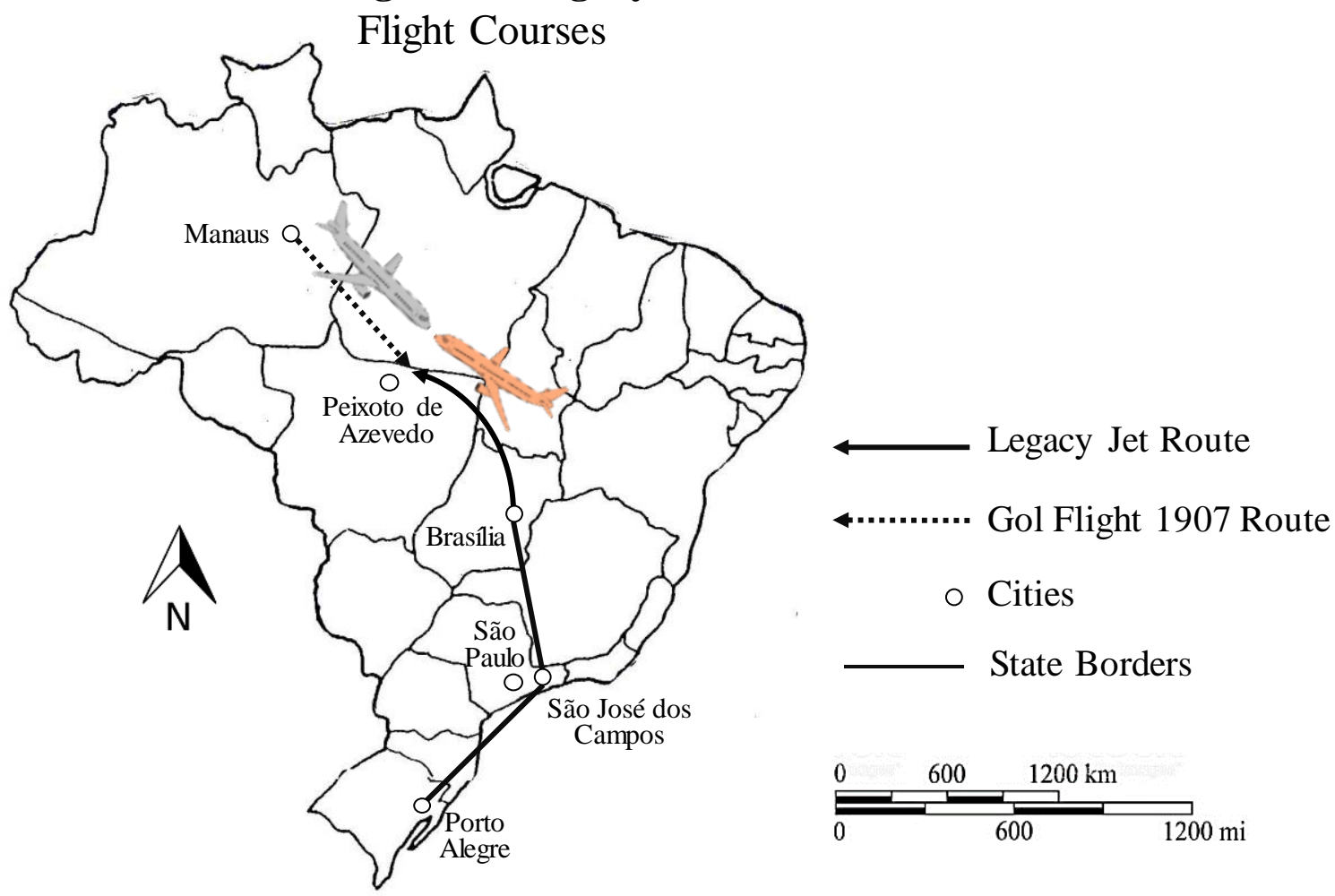

Source: Prepared by the authors. 
Figure 5 - Multi-facets of Crisis Management in HRO

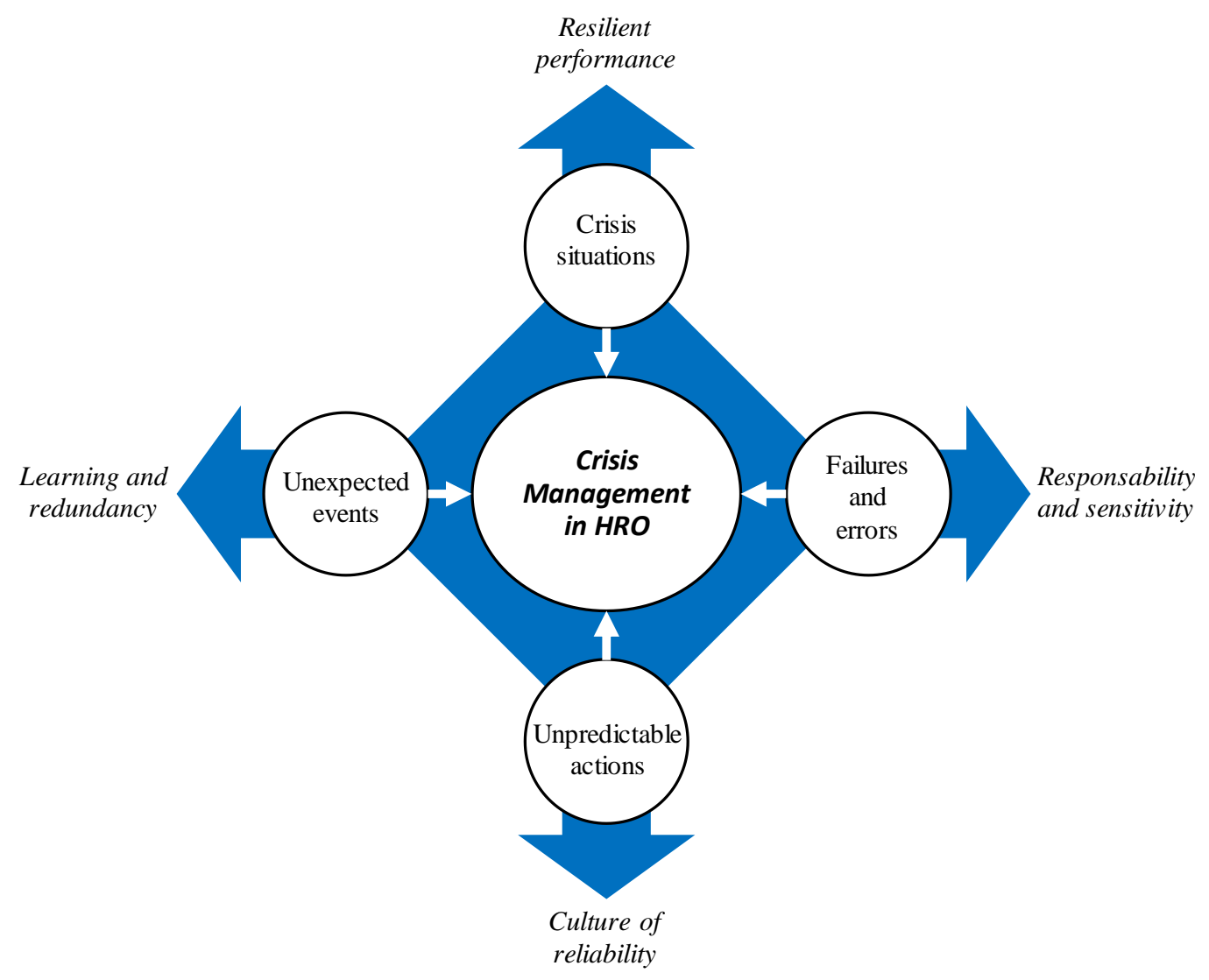

Source: Prepared by the authors. 
Table 1 - Flight Disasters in Brazilian territory

\begin{tabular}{|c|c|c|}
\hline Characteristics & $\begin{array}{c}\text { Case } 1 \\
\text { Gol and Legacy }\end{array}$ & $\begin{array}{c}\text { Case } 2 \\
\text { TAM } 3054\end{array}$ \\
\hline When & September, 2006 & July, 2007 \\
\hline Location & Brazil Northwest & Southeast Brazil \\
\hline Accident & Midair collision & Crash on land \\
\hline Victims & 154 deaths & 199 deaths \\
\hline Human Failures & $\begin{array}{l}\text { Communication failure between } \\
\text { air traffic control tower and pilots }\end{array}$ & $\begin{array}{l}\text { Failed operation of the } \\
\text { aircraft's braking system }\end{array}$ \\
\hline Technical Failures & Inoperative TCAS & Jammed thrust reverser \\
\hline \multirow{2}{*}{$\begin{array}{l}\text { Organizational } \\
\text { Management }\end{array}$} & $\begin{array}{c}\text { Latent errors: Historical dispute } \\
\text { between flight controllers }\end{array}$ & $\begin{array}{l}\text { Latent errors: Previously } \\
\text { reported reverser failure. }\end{array}$ \\
\hline & $\begin{array}{l}\text { Reliability: } \\
\text { technical and social }\end{array}$ & $\begin{array}{l}\text { Reliability: } \\
\text { technical and social }\end{array}$ \\
\hline
\end{tabular}

Source: Prepared by the authors. 
Table 2 - Lessons from flight disasters

\section{Lessons from flight disasters}

\section{Human Errors \\ Technical Failures}

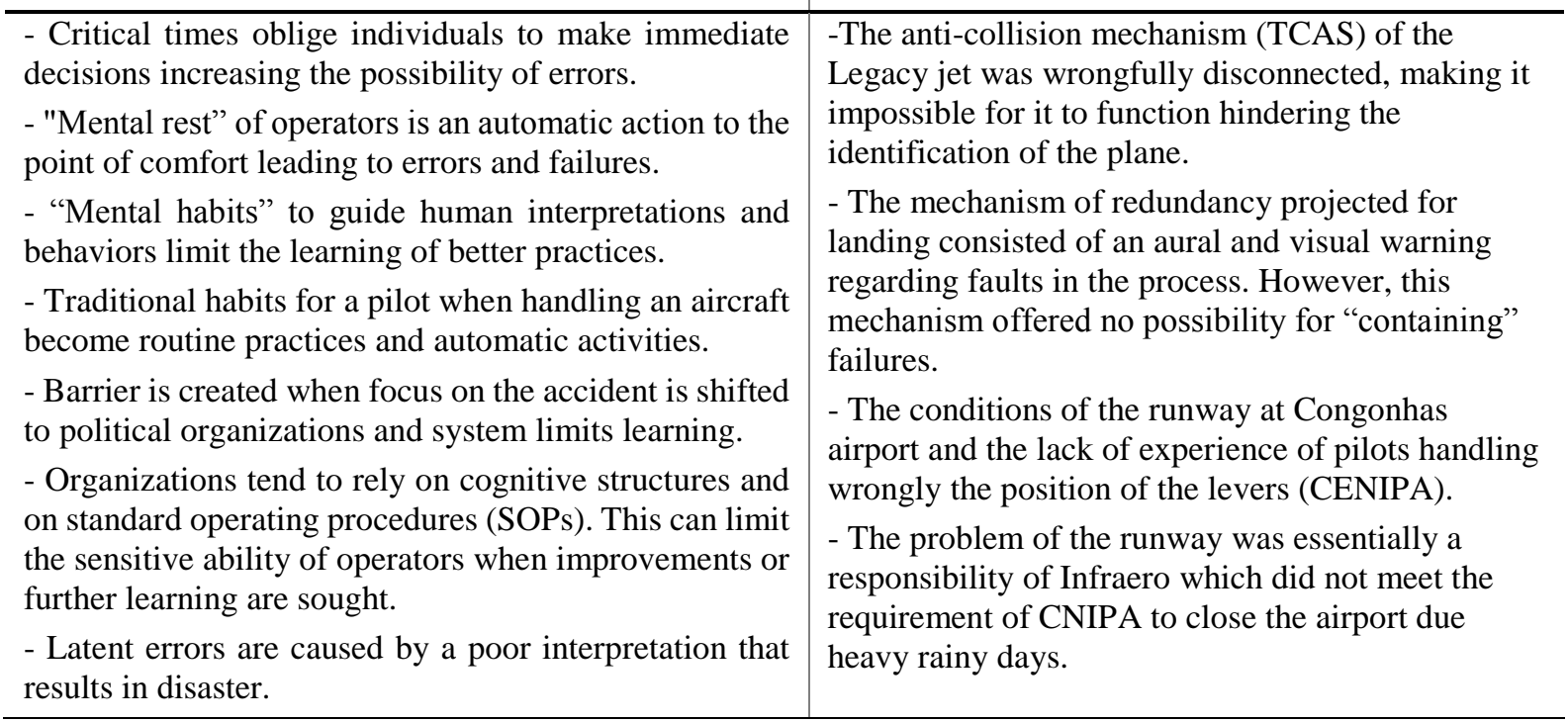

Source: Prepared by the authors. 